\title{
The learning experiences and outcomes of medical students in a longitudinal integrated clerkship and traditional block rotations in Taiwan: a comparative and qualitative study
}

\author{
Yaw-Wen Chang \\ National Defense Medical Center \\ Wen-Hui Fang \\ National Defense Medical Center \\ Wen-Chii Tzeng \\ National Defense Medical Center \\ Pauling Chu \\ National Defense Medical Center \\ Senyeong Kao ( $\square$ kao@ndmctsgh.edu.tw ) \\ National Defense Medical Certer
}

\section{Research article}

Keywords: Undergraduate, Longitudinal integrated clerkship, Mix-methods research, Curriculum evaluation, Clinical teaching and learning

Posted Date: February 18th, 2020

DOl: https://doi.org/10.21203/rs.2.23908/v1

License: (c) (i) This work is licensed under a Creative Commons Attribution 4.0 International License.

Read Full License 


\section{Abstract}

Background An increasing number of medical schools worldwide are implementing longitudinal integrated clerkships (LICs), but few schools in East Asia have done the same. The study explored and compared learning experiences and academic performances of LIC and traditional block rotation (TBR) students at a metropolitan tertiary teaching hospital in Taiwan.

Methods This study employed qualitative and quantitative methods. We used semi-structured interviews to explore the learning experience of the medical students in their fifth-year clerkship and analyzed the data with a general inductive approach. We also compared the students' academic performance, including the scores of their clinical performance, medical record writing, written tests, and the objective structured clinical exam.

Results There were 12 LIC and 14 TBR students who participated in interviews. We identified four major themes in their learning experiences. (1) Clinical learning: the importance of active learning, the difference between textbook knowledge and clinical practice, and opportunistic (TBR) versus contextual (LIC) learning. (2) With patients: companionship with patients (TBR and LIC) and bridging the gap between physicians and patients (LIC). (3) With preceptors: apprenticeship (for LIC) and difficulty communicating with preceptors (for TBR). (4) Doctor-patient relationship: interaction and communication. Comparing the learning outcomes, the LIC students scored higher on preceptor-rated assessments, and both groups exhibited comparable performance on written tests and the objective structured clinical examination.

Conclusion Although students' learning experience differed in some respects according to their curricula, they had a comparable academic performance.

\section{Background}

The first year of a clerkship is crucial for medical education because students experience a transition in terms of their learning environment (from a classroom to the workplace) and role (from a student to a physician) [1]. In the past century, developments in medical knowledge and technology have changed the manner in which medicine is studied. However, the model of clinical clerkship remains the same: it involves a sequence of short rotations through various specialties. A longitudinal integrated clerkship (LIC) is an innovative clinical training model based on the principle of educational continuity [2]. The characteristics of LIC are that medical students (1) participate in the comprehensive care of patients over time, (2) participate in continual learning relationships with clinicians of the patients, and (3) meet core clinical competencies across multiple disciplines simultaneously [3].

Numerous medical schools in the United States, the United Kingdom, Australia, Canada, and South Africa have implemented various LICs [3,4], particularly in rural or remote areas and some in urban-community settings [4]. A few examples of LICs in urban academic hospitals are Parnassus Integrated Student Clinical Experiences of the University of California, San Francisco in the United States, and Flinders Longitudinal Integrated Flinders Training of Flinders University in Australia $[5,6]$. Few medical schools in 
Asia have implemented community-based curricula [7, 8]. The National Defense Medical Centre is the first medical school in Taiwan that provides a hospital-based LIC program.

Medical students may have different learning experiences and outcomes according to their curricula. Relevant studies have reported comparable academic performance between students in LICs and in traditional block rotations (TBRs) [9-11]. Some studies have compared the learning experiences of students with LICs and TBRs and reported that LIC students engage more in patient care, have greater confidence in their clinical skills, and feel more prepared for internships [11-13]. However, most LICs in the aforementioned studies have a rural or community-based curriculum; few studies have compared the educational effects of a tertiary hospital-based LIC and TBR. To fill a literature gap, this study examined the experiences and perceptions of medical students in LIC and TBR curricula in an urban academic hospital.

\section{Methods}

\section{Introduction of a tri-service general hospital longitudinal integrated clerkship}

The Tri-Service General Hospital LIC (TS-LIC) was initiated in 2010, and it employs the model of the Harvard Medical School-Cambridge Integrated Clerkship [2]. The TS-LIC is an inpatient-dominant, hospital-based, and blended-type LIC [4] and is conducted at a tertiary teaching hospital affiliated to National Defense Medical Center, Taipei, Taiwan. The TS-LIC is implied in the fifth year of the six-year medical program. It requires six months and includes the major disciplines of the core clerkship. Each year, the TS-LIC enrolls 12 medical students (approximately $10 \%$ of the class) who participate voluntarily and are selected by lottery. Each LIC student is paired with a preceptor from a different discipline, namely internal medicine (IM), surgery, obstetrics and gynecology (OB-GYN), pediatrics, psychiatry, and family medicine. The first eight weeks of the LIC are referred to as the immersion phase. During this phase, LIC students are rotated every two weeks in IM, surgery, OB-GYN, and pediatrics. The students learn the fundamentals of inpatient care, ward routines, cooperation with team members, and familiarity with hospital life. In the following four months, the LIC students simultaneously participate in inpatient care, outpatient clinics, patient follow-ups in these disciplinaries (Appendix 1). Other medical students participated in TBRs; this conventional clerkship curriculum provides rotational training with a period of two weeks for each discipline.

\section{Study design}

This study employed qualitative and quantitative methods, wherein fifth-year medical students at the TriService General Hospital were subjected to semi-structured interviews during the 2015-2016 academic year; and their academic performance was compared.

The sample included 113 fifth-year medical students, 12 of whom (five men and seven women) participated in the TS-LIC. It included all LIC students and some TBR students. The TBR students were enrolled through snowball sampling. 


\section{Data collection and analysis}

Semi-structured interviews were performed for data collection from February to April 2016, the second half phase of the $5^{\text {th }}$ year clerkship. The interviewees signed a consent form agreeing to the audiorecording of their interviews. During the interview, interviewees were asked to describe their thoughts and experiences regarding their clerkships as well as discuss their interactions with preceptors, medical team members, and patients and other significant events (interview protocol, Appendix 2). The approximate duration of each interview was 30-60 minutes, and the contents were audio-recorded and subsequently transcribed. Interviewees were asked to review the completed transcripts and confirm the accuracy of the content.

A general inductive approach was used for data analysis $[14,15]$. First, two primary researchers (Y.C and W.F) reviewed the three to five copies of transcripts and established initial encoding. The two primary researchers and a research assistant then encoded the remaining three to five copies according to the initial encoding and developed a classification code manual. The primary researchers and research assistants then encoded the remaining transcripts. Thus, each transcript was encoded by the research assistant and one of the primary researchers; the two encoders then inspected and discussed the encoding results to reach a consensus. The final subjects and examples were presented to other members of the research team, who inspected the material and reached a consensus. NVivo version 11 (QSR International Pty Ltd, Doncaster, Victoria, Australia) was used to organize and retrieve the coded data.

Student academic performance was determined through four assessments and presented in the form of a final academic score. The clinical performance assessment included subjective evaluation comprising qualitative descriptions of student clinical performance and a summative score provided by residents and attending physicians in each rotation. All medical students completed a minimum of one admission note during each rotation. The attending physicians reviewed and corrected these medical records and rated the students in accordance with structured rating instructions. All students were subjected to several written tests and an objective structured clinical examination throughout and the end of the year, respectively. The final academic score reflected the combined score for these assessments.

\section{Ethical approval}

This study was reviewed and approved by the Tri-Service General Hospital Institutional Review Board (TSGHIRB 2-103-05-081).

\section{Results}

A total of 12 LIC and 14 TBR students participated in the interviews. Table 1 presents the demographics of the sampled students. 
On the basis of the content of the student interviews, four primary themes were identified: clinical learning, interactions with patients, interactions with the preceptor team, and doctor-patient interactions. Table 2 shows the similarity and dissimilarity between the perceptions and experiences of LIC and TBR students.

\section{Clinical learning}

Both LIC and TBR students acknowledged that self-directed learning is crucial during clerkships. Learning in the hospital was usually scattered and incidental. Clinical teaching generally occurred during ward rounds and clinical encounters, and the contents were situation related, focusing on diseases or symptoms of real patients present at that moment. A substantial amount of free time was available between teaching activities; thus, students had to search for opportunities for learning, because without any active learning, they might have learned less. Except for the didactics, an informal discussion was the primary teaching method used in clinical teaching; advance preparation by students enabled the preceptors to interact better with and improve teaching for students. Otherwise, the preceptors would ask students to study in advance to ensure that they had a basic understanding before discussions.

If you do not actively search for learning opportunities, and if the residents or interns do not actively teach you, you do not know what to do at the hospital. (R-03)

During ward rounds, we have a daily patient list. The attending would instruct me to take a look at a particular disease, stating that this case is very interesting, and ask me to study on it. They then discuss the background knowledge with us at the nursing station. (L-02)

The attending focuses on our cases for discussion and guides our thinking. Thus, they keep asking questions, and we must keep answering those questions until we cannot answer one. They then ask you to find the answer to that question through research. (L-01)

In the early stages of clerkships, both groups of students encountered the same problem of lack of awareness regarding how to apply the knowledge acquired during school to clinical care. All medical students stated that they memorized the teachings in the school and did not genuinely understand the acquired knowledge until after experiencing actual interactions with patients in hospitals.

I feel like the things I studied in the past cannot be practically applied to clinical work. (L-04)

During the fourth-year learning process, you are unable to grasp the key points or have a fuzzy concept. It is only in the fifth year that you realize, [...] you now finally understand the concepts that were confusing before. (R-13)

LIC students stated that longitudinality provided them with a thorough understanding of diseases and treatments. TBR students generally encountered opportunistic learning content and thus learned through observation. 
I think the advantage of LIC is that you acquire a thorough understanding of diseases and truly remember them. However, in the TBRs, you observe many common diseases in a short duration and thus may not remember each of them. ( $L-05)$

Primarily, we share information with patients: [...] what we have seen in the operating room or the experiences of patients we have cared for, [...] the general follow-up process, and the duration and approach of their treatments. (L-10)

In TBR [teaching methods], the diseases, types of cases, and patient symptoms you encounter influence what your preceptor teaches you. However, the acquired knowledge is scattered and unsystematic. (R-05)

\section{Interactions with patients}

In the early stages of clerkships, both groups of students were anxious during interactions with patients. Although students attended courses in school on history-taking, physical examinations, and communication skills, they were overwhelmed when encountering new patients on their own.

There was a time that my mind was completely blank when I faced a new patient; that is, I was very nervous and did not know what to say. (R-04)

Especially when we first entered the hospital, we really did not know what to say to the patient. We could only awkwardly say things like 'Oh, how have you been? Have you gone out for a walk?' Just saying the same things every day; we did not know what else to say. (L-10)

The descriptions of patient interactions by the students reveal differences between the two types of curriculum designs. During interactions with patients, most LIC students could completely describe patient and family backgrounds as well as physical and psychological changes before and after the occurrence of diseases; they could also describe their interactions with patients during follow-ups. LIC students conducted longitudinal follow-ups with patients. Under these circumstances, students could interact with the patients throughout the complete course of a disease, thoroughly understand the relationship between the disease and lifestyle of patients, and establish a meaningful relationship with them. Therefore, LIC students bridged the gap between physicians and patients and provided patients with attention and support.

I started to care for a patient with heart failure in the first week; [...] over the course of 4 weeks, I was constantly observing this patient. [...] I clearly observed the process of the attending physician modifying the treatment plan and thought it was very useful. (L-02)

In school, teachers only taught disease-related information. You learn about the development, treatment, and prognosis of a particular disease. However, teachers did not talk about the thoughts of patients with such diseases or the impact of the disease on patients' families. Because they [patients] are willing to share, I realized that this disease actually caused different responses in different people. (L-09) 
I think sometimes we play a kind of bridging role. For example, when making rounds, sometimes the patient is very nervous and forgets what they should ask. Afterward, they see us and say things like "Oh right, I wanted to ask you something." Then, we ask the attending these questions on behalf of the patients. [...] In the past, you would never think that patients could actually be nervous, too or that they would just not think to ask these questions at the time. I only realized that during such interactions. (L-03)

TBR students had shorter interactions with patients. These interactions primarily occurred during hospitalization; students did not always have the opportunity to continue to provide care after discharge and thus rarely performed follow-ups. In their explanations of interactions with patients, most TBR students provided fragmented descriptions of communications between the attendings or resident doctors and patients, or they described patient disease processes. Few students attempted to understand patient backgrounds. Most interactions between TBR students and patients had a specific purpose, such as recording a patient history to accomplish an assigned task. Sometimes students could serve as companions and express care and sympathy.

For example, the attending physicians tell me to ask the patients for their history, and I try to ask, but I am still new at this and do not know what to ask and thus can only follow the most basic standards from the textbook. When I ask, although I get an answer, there is a lack of... a human touch. Sort of like when a computer gives you a questionnaire to answer. I have only asked you where you feel uncomfortable and how uncomfortable you are. Although these things are necessary, I feel I should add some greetings and inquiries or have a chat with the patients, that is, consider them a friend. (R-06)

\section{Interactions with preceptors and house staff}

Curriculum arrangements for the two groups were different; thus, learning processes were different. In both groups, the attendings were the primary instructors at the hospital and the primary sources of clinical knowledge for students. In addition to small group lectures, teaching and learning majorly occurred in ward rounds or bedside teaching. During the teaching process, the attendings generally used the interactive discussion to direct student learning. However, considerable differences were observed in the interactions of TBR students with attendings of different disciplines; the level of the busyness of the attendings influenced teaching outcomes. By contrast, LIC students had continuous mentoring relationships with the attendings. The teaching roles of the residents for students were undefined, and their interactions were not close.

Basically, the attendings kindly respond to you. Because they know the goals of the clerkship curriculum, they will teach you. Of course, some [attendings] may actually be busy and have other things or research to do. They may not have much time [to teach]. (R-05)

Because you follow one preceptor for six months, you can better understand the job description of a physician in this department. Also, the preceptor better understands your learning situation, so they are more willing to let you do things independently. (L-09) 
[LIC students] are more familiar with attendings. The attendings definitely remember your name and understand you more. Relatively speaking, you can ask them questions or ask for help, and they won't refuse as much. [...] The advantage of LIC is that if you really want to learn something, the preceptors are generally happy to help you learn it. (L-07)

Interns and students interact frequently. This behavior is more evident in TBR students because they spend more time in wards, and the ages and nature of work of the interns and TBR students were similar. Therefore, TBR students generally learn ward work from interns. In the early stages of clerkships, TBR students experienced difficulty when assimilating into clinical teams because they were unfamiliar with the clinical workflow. Interpersonal relationships influenced this learning process. LIC students primarily learned from attendings; however, they learned ward work and basic clinical skills from interns.

The things we want to learn are mostly clinical work encountered during internships, and we learn that from interns. They also know more about what to teach us and what we will encounter in the next 1-2 years. (R-01)

Sometimes, I feel like I'm being left behind; [...] much of the medical terms they use are abbreviations or codes, leaving me confused. I don't know what I can do to keep myself from sitting on the sidelines, so that I can participate and learn because I am very afraid to bother the attendings since they are busy. (R03)

Because I am familiar with some interns, I already know how to write admission notes and SOAP notes and enter orders. [...] Some students may not be familiar with interns, or because the interns are very busy, they might not be bold enough to say "Please teach me!" I might know how to do something while my classmates still do not. (R-02)

\section{Doctor-patient relationships}

Both groups of students demonstrated high levels of interest in doctor-patient interactions during their clerkships. Students observed the communication practices and modes of interaction between attendings and patients, and through these observations, they determined suitable communication methods accordingly.

Some attendings are very good at dealing with patients, thus helping you to learn how to handle patients in the future. $(\mathrm{R}-11)$

I think the way that they [the attending] explains things to patients is very careful, quite detailed, and structured, so it is easier for patients to understand. I think this is a key area where we can learn from our preceptors; that is, how we should communicate our medical knowledge to patients in a way that they can understand. (L-03)

\section{Academic performance}


Table 3 details the academic performance of LIC and TBR students. LIC students had higher scores in clinical performance $(94.79 \pm 0.78)$ compared with TBR interviewees $(91.29 \pm 1.68, p<0.001)$ and all TBR students $(91.00 \pm 1.32, p<0.001)$. LIC students had higher scores in medical record writing $(92.92 \pm 2.90)$ than all TBR students $(89.20 \pm 2.90, p<0.001)$; however, no significant difference was observed between the scores of LIC students and TBR interviewees (91.66 $\pm 2.88, p=0.268)$. Furthermore, no difference was observed between LIC and TBR students in scores on written tests and the objective structured clinical examination. Higher final academic score was demonstrated in LIC students then sampled and all TBR students.

\section{Discussion}

This study compared the experiences and perceptions of LIC and TBR students during their first year of clerkships. Four major themes were identified: clinical learning, interactions with patients, interactions with the preceptors and team members, and doctor-patient interactions. Among these themes, the two groups of students had some common experiences, particularly in clinical learning. However, because of the curriculum principles, LIC students had some distinctive experiences regarding long-term relationships with preceptors and patients.

At the beginning of the clerkship, the students were stressed because they assumed that they did not have sufficient knowledge and skills to practice in the workplace. This finding can be attributed to the decontextualized and nonintegrated nature of their preclinical studies [16]. During their interactions with patients and preceptors, the students emphasized their anxiety. They were concerned with appearing unknowledgeable in front of patients or supervisors, which is consistent with the perception of students reported in other studies $[17,18]$. Clinical learning in conventional clerkships has been considered opportunistic, brief, and fragmented because it depends on patient encounters [19-21]. However, in LICs, learning experiences in the workplace are not always comfortable $[22,23]$, which can be attributed to unplanned learning opportunities [24, 25] and insufficient knowledge or skills [23, 26].

A proactive, self-motivated, and enthusiastic approach is crucial for clinical learning [27]. Medical students must study independently and acquire knowledge from supervisors [28]. Active engagement with patients can enhance student learning [12]. In this study, students stated that they recognized the necessity of self-directed learning in the workplace. Learning in hospitals was fragmented and generally occurred during clinical activities. The preceptors and house staff wanted the students to prepare in advance because they did not have sufficient time to provide background knowledge.

Several studies have reported that junior staff members are the principal educators in teaching hospitals $[20,21,29,30]$. In this study, the attending physicians were recognized as the formal educators in the team. The interns primarily assisted students in adapting to hospital life. The residents were reported to have a high workload and thus did not frequently interact with first-year clerks. This phenomenon might be based on different educational designs. In this school, a clerkship only requires eight months for completion, whereas an internship requires two years (the sixth and seventh year). Clerks are rotated 
every two weeks among different units, whereas the interns are rotated monthly. Compared with the relationships between interns and residents, those between clerks and residents might be less intimate.

Communication skills are crucial for establishing doctor-patient relationships in medical practice. These skills can be taught using various methods, such as didactic lectures, videos, role-plays, interactions with standard patients, and simulations. However, most medical students learn verbal and nonverbal communication skills by observing their teachers and preceptors during daily practice [31]. Noncognitive characteristics, such as communication and relationship building, are considered valuable in clinical teachers [32]. In this study, both groups of students observed the modes of doctor-patient communications used by preceptors during rounds in clinics and wards.

Both groups of students primarily described themselves as observers. They stated that their interactions with patients generally included taking a patient history and conducting conversations with patients during daily visits. LIC students generally conducted patient follow-ups for a few weeks or months after discharge. They had more interactions with their patients, which resulted in the formation of closer connections. LIC students bridged the gap between physicians and patients and provided patients with care and support. In a relevant study, both LIC and TBR students could provide support to and share information about their care with patients; however, the LIC students could take on more advanced clinical roles than could TBR students when caring for their patients [13]. In another observational study, LIC students demonstrated more independent engagement in patient care in the later stage of the clerkship [33].

In this study, LIC students described a closer relationship with attendings. One of the fundamental principles for LICs is forming continuity relationships with faculty preceptors; students can benefit from such relationships. Students recognized by their preceptors can receive a more individualized and structuralized learning experience and can obtain tailored feedback [28, 34, 35].

\section{Strengths and limitations}

A review of relevant literature indicated that this is the first study to compare the learning experiences of LIC and TBR students in an East Asian country. The results might provide insight into student experiences and curriculum outcomes of East Asian LIC programmers. However, this study has some limitations. First, we could not be entirely blinded for the curriculum model of interviewees while analyzing the transcripts. Because the interviewees would mention about the requirements or the process of the curriculum. For example, the LIC students might mention follow-up patients, and the TBR students might talk about the rotations. But, during the process of interviewing, the research assistant did not know the curriculum type of interviewees and kept a neutral and open position to collect data. Second, the number of participants was small. In this academic year, twelve students participated LIC program. All LIC students were included, but only some TBR students were enrolled in this study. A larger number of participants could have provided more information and more diverse perspectives. However, we were continuing to enroll TBR students until the data saturation was achieved. Third, selection bias may be observed among TBR students because enrolment was performed through snowball sampling. A small difference was 
observed between TBR interviewees and the entire class in terms of academic performance, which raises a concern regarding the representativeness of the research findings. The students voluntarily applied for the LIC and were selected at random. An inevitable bias of personal behavioral preferences could be present. However, the research team, senior clinical teachers, and sampled students recognized our findings in this study. Fourth, the possible effect of personal relationships on subjective assessments of students, such as clinical performance and medical record writing, cannot be discounted. However, the outcomes for LIC and TBR students were comparable. Finally, the curriculum design of the TS-LIC was different from that of most LICs. North America, Australia, and the United Kingdom generally have urbancommunity or rural-based LICs. The TS-LIC is an urban hospital-based program, and the curriculum emphasizes inpatient care. However, the same principles were followed in the curriculum design.

\section{Conclusion}

Medical students in TS-LIC and TBRs follow different paths to reach the same destination. They hold different perceptions during the early stages of becoming a doctor. In this study, their learning experiences were similar in some aspects and varied in others. Students enrolled in these two curricula experienced difficulty during clinical learning and interactions with patients in the early stage of clerkships. LIC students learned within the context of continuity of care, supervision, and care. TBR students experienced idiosyncratic and fragmented learning. Through engagement in clinical counseling or ward rounds, both groups of students observed the modes used by attendings throughout doctorpatient interactions. In the end, the LIC students had a better score in clinical performance and comparable outcomes in the other areas. In the design of the clerkship curricula for both LIC and TBR, possible future improvements include bridging the gap between textbook knowledge and clinical practice. Moreover, future programs can focus on assisting medical students by helping them to quickly adapt to hospital work, assimilating them into medical teams, and directing their learning in the workplace.

\section{Abbreviations}

LIC: longitudinal integrated clerkship; TS-LIC: Tri-Service General Hospital longitudinal integrated clerkship; TBR: traditional block rotation; OSCE: objective structured clinical examination

\section{Declarations}

\section{Ethics approval and consent to participate}

This study was reviewed and approved by the Tri-Service General Hospital Institutional Review Board (TSGHIRB 2-103-05-081).

\section{Consent for publication}

Not applicable 
Availability of data and materials

The datasets generated during and/or analysed during the current study available from the corresponding author on reasonable request.

\section{Competing interests}

The authors report no conflicts of interest. The authors alone are responsible for the content and writing of this article.

\section{Funding}

This study was financially supported by grants from the Ministry of Science and Technology, Taiwan (MOST104-2511-S-016-002).

\section{Authors' contributions}

Conception and design of study: YC, WT, PC, SK; acquisition of data: YC, WF; analysis and interpretation of data: YC, WF, WT, PC, SK; drafting the manuscript: YC; revision the manuscript: YC, SK; approval of the version of the manuscript: YC, WF, WT, PC, SK.

\section{Acknowledgements}

The authors would like to thank Dr. David Hirsh and Dr. Honghe Li from HMS-Cambridge Integrated Clerkship, Boston and Cambridge, MA, USA for their thoughtful edits and thank the study participants for their time.

\section{References}

1. Dubé TV, Schinke RJ, Strasser R, Couper I, Lightfoot NE. Transition processes through a longitudinal integrated clerkship: a qualitative study of medical students' experiences. Med Educ. 2015;49:102837.

2. Hirsh D, Ogur B, Thibault G, Cox M. "Continuity" as an organizing principle for clinical education reform. N Engl J Med. 2007;356:858-66.

3. Norris TE, Schaad DC, DeWitt D, Ogur B, Hunt DD, Consortium of Longitudinal Integrated C. Longitudinal integrated clerkships for medical students: an innovation adopted by medical schools in Australia, Canada, South Africa, and the United States. Acad Med. 2009;84:902-7.

4. Worley P, Couper I, Strasser R, Graves L, Cummings BA, Woodman R, et al. Consortium of longitudinal integrated clerkships research c: a typology of longitudinal integrated clerkships. Med Educ. 2016;50:922-32.

5. Heddle W, Roberton G, Mahoney S, Walters L, Strasser S, Worley P. Challenges in transformation of the "traditional block rotation" medical student clinical education into a longitudinal integrated 
clerkship model. Educ Health (Abingdon). 2014;27:138-42.

6. Poncelet A, Bokser S, Calton B, Hauer KE, Kirsch H, Jones T, et al. Development of a longitudinal integrated clerkship at an academic medical center. Med Educ Online. 2011;doi: 10.3402/meo.v16i0.5939.

7. Sarraf-Yazdi S, Cook S, Kamei RK. Calculated overhaul versus cultivating the status quo in clinical education. Ann Acad Med Singapore. 2014;43:132-33.

8. Takamura A, le K, Takemura Y. Overcoming challenges in primary care education: a trial of a longitudinal integrated clerkship in a rural community hospital setting in Japan. Educ Prim Care. 2015;26:122-26.

9. Walters L, Greenhill J, Richards J, Ward H, Campbell N, Ash J, et al. Outcomes of longitudinal integrated clinical placements for students, clinicians and society. Med Educ 2012;46:1028-41.

10. Woloschuk W, Myhre D, Jackson W, McLaughlin K, Wright B. Comparing the performance in family medicine residencies of graduates from longitudinal integrated clerkships and rotation-based clerkships. Acad Med. 2014;89:296-300.

11. Caygill R, Peardon M, Waite $C$, Wright J. Comparing a longitudinal integrated clerkship with traditional hospital-based rotations in a rural setting. Med Teach. 2017;39:520-26.

12. Shahi R, Walters $L$, Ward $H$, Woodman RJ, Prideaux D. Clinical participation of medical students in three contemporary training models. Med Educ. 2015;49:1219-28.

13. Hauer KE, Hirsh D, Ma I, Hansen L, Ogur B, Poncelet AN, et al. The role of role: learning in longitudinal integrated and traditional block clerkships. Med Educ. 2012;46:698-710.

14. Miles MB, Huberman AM. Qualitative data analysis : an expanded sourcebook, 2nd edn. Thousand Oaks: Sage Publications; 1994.

15. Thomas DR. A general inductive approach for analyzing qualitative evaluation data. Am J Eval. 2016;27:237-46.

16. O'Brien B, Cooke M, Irby DM. Perceptions and attributions of third-year student struggles in clerkships: do students and clerkship directors agree? Acad Med. 2007;82:970-78.

17. Godefrooij MB, Diemers AD, Scherpbier AJJ. Students' perceptions about the transition to the clinical phase of a medical curriculum with preclinical patient contacts; a focus group study. BMC Med Educ 2010;10:28.

18. Dornan T, Bundy C. What can experience add to early medical education? Consensus survey. BMJ. 2004;329:834.

19. Bloomfield L, Harris P, Hughes C. What do students want? The types of learning activities preferred by final year medical students. Med Educ. 2003;37:110-18.

20. Seabrook MA, Woodfield SJ, Papagrigoriadis S, Rennie JA, Atherton A, Lawson M. Consistency of teaching in parallel surgical firms: an audit of student experience at one medical school. Med Educ. 2000;34:292-98. 
21. Ogur B, Hirsh D, Krupat E, Bor D. The Harvard Medical School-Cambridge integrated clerkship: an innovative model of clinical education. Acad Med. 2007;82:397-404.

22. Hirsh D, Gaufberg E, Ogur B, Cohen P, Krupat E, Cox M, et al. Educational outcomes of the Harvard Medical School-Cambridge integrated clerkship: a way forward for medical education. Acad Med. 2012;87:643-50.

23. Couper I, Worley PS, Strasser R. Rural longitudinal integrated clerkships: lessons from two programs on different continents. Rural Remote Health. 2011;11:1665.

24. Worley P, Silagy C, Prideaux D, Newble D, Jones A. The parallel rural community curriculum: an integrated clinical curriculum based in rural general practice. Med Educ 2000;34:558-65.

25. Couper I. Evaluation of the comprehensive community clerkship in the Northern Ontario School of Medicine. Final Report. Johannesburg: University of the Witwatersrand; 2008. Accessed: 2 July 2020. DOI: 10.13140/RG.2.2.36236.36485

26. Couper I. Evaluation of the Parallel Rural Community Curriculum at Flinders University of South Australia, in the Context of the GEMP Year 3. Final Report. Johannesburg: University of the Witwatersrand; 2006. https://www.wits.ac.za/media/migration/files/cs-38933-fix/migratedpdf/pdfs-5/couper\%20evaluation\%20final\%20report\%202006.pdf. Accessed: 2 July 2020.

27. O'Brien BC, Hirsh D, Krupat E, Batt J, Hansen LA, Poncelet AN, et al. Learners, performers, caregivers, and team players: Descriptions of the ideal medical student in longitudinal integrated and block clerkships. Med Teach. 2016;38:297-305.

28. Hauer KE, O'Brien BC, Hansen LA, Hirsh D, Ma IH, Ogur B, et al. More is better: students describe successful and unsuccessful experiences with teachers differently in brief and longitudinal relationships. Acad Med. 2012;87:1389-96.

29. Remmen R, Denekens J, Scherpbier A, Hermann I, van der Vleuten C, Royen PV, et al. An evaluation study of the didactic quality of clerkships. Med Educ. 2000;34:460-64.

30. van der Hem-Stokroos HH, Daelmans HE, van der Vleuten CP, Haarman HJ, Scherpbier AJ. A qualitative study of constructive clinical learning experiences. Med Teach. 2003;25:120-26.

31. Odhayani A, Ratnapalan S. Teaching communication skills. Can Fam Physician. 2011;57:1216-18.

32. Sutkin G, Wagner E, Harris I, Schiffer R. What makes a good clinical teacher in medicine? A review of the literature. Acad Med. 2008;83:452-66.

33. O'Brien BC, Poncelet AN, Hansen L, Hirsh DA, Ogur B, Alexander EK, et al. Students' workplace learning in two clerkship models: a multi-site observational study. Med Educ. 2012;46:613-24.

34. Teherani A, O'Brien BC, Masters DE, Poncelet AN, Robertson PA, Hauer KE. Burden, responsibility, and reward: preceptor experiences with the continuity of teaching in a longitudinal integrated clerkship. Acad Med. 2009;84:S50-53.

35. Cuncic C, Regehr G, Frost $H$, Bates J. It's all about relationships: a qualitative study of family physicians' teaching experiences in rural longitudinal clerkships. Perspect Med Educ. 2018;7:100109. 


\section{Tables}

Table 1 Demographics for the longitudinal integrated clerkship and traditional block rotation medical students

\begin{tabular}{llll}
\hline Gender & LIC & TBR interviewee & Total class \\
& $(\mathrm{n}=12)$ & $(\mathrm{n}=14)$ & $(\mathrm{n}=113)$ \\
& $\mathrm{n}(\%)$ & $\mathrm{n}(\%)$ & $\mathrm{n}(\%)$ \\
\hline Male & $5(41.7)$ & $7(50.0)$ & $86(76.1)$ \\
Female & $7(58.3)$ & $7(50.0)$ & $27(23.9)$ \\
\hline
\end{tabular}

Abbreviations: LIC, longitudinal integrated clerkship; TBR, traditional block rotation

Table 2 Themes of learning experiences in the $5^{\text {th }}$ year clerkship from longitudinal integrated clerkship and traditional block rotation medical students 


\section{Clinical}

learning

\section{Acknowledgement of the importance of active learning}

- After students entered the hospital, learning became scattered and incidental. Self-directed learning became crucial. Without active study, students might learn less.

- Preceptors mostly used discussions to teach. Advance preparation by students enabled the preceptors to teach more.

\section{Inability to apply textbook knowledge}

- Did not know how to apply knowledge learned in school in clinical settings; only genuinely understood this knowledge following contact with patients.

\section{Contextual learning}

- Gained a deeper understanding of diseases and treatments.

\section{Opportunistic learning}

- What students learned depended on what they saw.

\section{Interactions}

with patients

\section{Nervousness during interactions with patients}

- During the early stages of these interactions, students felt nervous and believed that their own knowledge was insufficient.

\section{Adoption of bridging roles}

- Continuous follow-up of patients enabled students to fully track changes in disease activity.

- Students gained a deeper understanding of patients and the relationship between diseases and quality of life, and established close relationships with patients.

- Could provide care and support and bridge the gap between physicians and patients.

\section{Accompanying patients}

- Interactions with patients were mostly when taking history.

- Were more like companions than healers.

- Could express care and empathy.

\section{Interactions Teaching roles of the team members \\ with preceptors - Attendings were formal educators and primarily made rounds and taught classes. \\ and team - Teaching roles of residents were unclear; they mostly passed on knowledge. \\ members - Interns were the primary instructors who helped students in adapting to hospital life and developing relevant skills.}

- The degree to which team members were busy with clinical work influenced teaching. 


\section{Apprenticeship model}

- There was a remarkably close longitudinal supervision relationship between attendings and students.
Difficulty assimilating into teams during early

stages

- Students were unfamiliar with the clinical workflow and content and were unable to assimilate into teams during the early stages.

- Interpersonal relationships influenced the learning process.

\section{Doctor-patient Interest in doctor-patient interactions}

relationships - Students demonstrated high levels of interest in observing modes of communication and interaction between attending physicians and patients and identified the methods that best suited them through such observation.

Table 3 Academic performance of longitudinal integrated clerkship and traditional block rotation students at the end of $5^{\text {th }}$ year clerkship

\begin{tabular}{|c|c|c|c|c|c|c|}
\hline \multirow[t]{3}{*}{ Assessment } & A. LIC all & B. TBR interviewees & C. TBR all & A vs B & $\mathrm{B}$ vs $\mathrm{C}$ & A vs $C$ \\
\hline & $(\mathrm{n}=12)$ & $(\mathrm{n}=14)$ & $(\mathrm{n}=101)$ & & & \multirow[b]{2}{*}{$p$-value ${ }^{\dagger}$} \\
\hline & mean $\pm S D$ & mean $\pm \mathrm{SD}$ & mean $\pm S D$ & $p$-value ${ }^{\dagger}$ & $p$-value ${ }^{\dagger}$ & \\
\hline Clinical performance & $94.79 \pm 0.78$ & $91.43 \pm 1.60$ & $91.00 \pm 1.32$ & $<0.001$ & 0.261 & $<0.001$ \\
\hline Medical record writing & $92.92 \pm 2.90$ & $91.66 \pm 2.88$ & $89.20 \pm 2.90$ & 0.280 & 0.003 & $<0.001$ \\
\hline Written tests & $66.50 \pm 5.20$ & $63.86 \pm 6.40$ & $65.49 \pm 6.36$ & 0.264 & 0.372 & 0.596 \\
\hline OSCE & $89.50 \pm 1.45$ & $89.86 \pm 0.53$ & $89.57 \pm 0.90$ & 0.398 & 0.254 & 0.802 \\
\hline Final academic score & $90.17 \pm 1.36$ & $88.34 \pm 1.46$ & $87.64 \pm 1.29$ & 0.003 & 0.064 & $<0.001$ \\
\hline
\end{tabular}

${ }^{\dagger}$ Independent student t test

Abbreviations: LIC, longitudinal integrated clerkship; TBR, traditional block rotation; OSCE, objective structured clinical examination 


\section{Supplementary Files}

This is a list of supplementary files associated with this preprint. Click to download.

- Appendix2.docx

- Appendix1.docx 